Review

\title{
Potential mechanisms linking psychological stress to bone health
}

\author{
Jia-Sheng Ng, Kok-Yong Chin ${ }^{凶}$ \\ Department of Pharmacology, Faculty of Medicine, Universiti Kebangsaan Malaysia, Cheras 56000, Malaysia. \\ $\triangle$ Corresponding author: Level 17, Preclinical Building, Department of Pharmacology, Faculty of Medicine, Universiti Kebangsaan Malaysia, Jalan Yaacob Latif, Bandar Tun \\ Razak, Cheras 56000, Malaysia. E-mail: chinkokyong@ppukm.ukm.edu.my; Tel.: +603-9145-9573. \\ (C) The author(s). This is an open access article distributed under the terms of the Creative Commons Attribution License (https://creativecommons.org/licenses/by/4.0/). \\ See http://ivyspring.com/terms for full terms and conditions.
}

Received: 2020.07.14; Accepted: 2020.11.30; Published: 2021.01.01

\begin{abstract}
Chronic psychological stress affects many body systems, including the skeleton, through various mechanisms. This review aims to provide an overview of the factors mediating the relationship between psychological stress and bone health. These factors can be divided into physiological and behavioural changes induced by psychological stress. The physiological factors involve endocrinological changes, such as increased glucocorticoids, prolactin, leptin and parathyroid hormone levels and reduced gonadal hormones. Low-grade inflammation and hyperactivation of the sympathetic nervous system during psychological stress are also physiological changes detrimental to bone health. The behavioural changes during mental stress, such as altered dietary pattern, cigarette smoking, alcoholism and physical inactivity, also threaten the skeletal system. Psychological stress may be partly responsible for epigenetic regulation of skeletal development. It may also mediate the relationship between socioeconomic status and bone health. However, more direct evidence is required to prove these hypotheses. In conclusion, chronic psychological stress should be recognised as a risk factor of osteoporosis and stress-coping methods should be incorporated as part of the comprehensive osteoporosis-preventing strategy.
\end{abstract}

Key words: cortisol; hormones; mental stress; osteopenia; osteoporosis

\section{Introduction}

Osteoporosis is a skeletal degenerative disease characterised by deterioration of bone microarchitecture and mass, which subsequently leads to fractures. Worldwide, 8.9 million osteoporotic fractures occur annually, which translate to a fracture every 3 seconds [1]. Approximately 20 million Europeans aged over 50 years old suffered from osteoporosis, and 2.7 million experienced an osteoporotic fracture in 2017. This number is projected to increase by $23 \%$ in 2030 . Financially, osteoporotic fractures incur substantial healthcare costs, amounting to 37.5 million euros in 2017 and is estimated to increase by $27 \%$ in 2030 [2]. The increasing prevalence of osteoporotic fractures calls for the need to identify high-risk individuals so that early intervention could be implemented.

Psychological stress occurs when an individual perceives an environment demand exceeding his/her ability to adjust. It can be measured as self-perceived stress and the effects of negative events. Chronic psychological stress is damaging to health because it produces long-term physiological, emotional, and behavioural changes that alter disease susceptibility [3]. Chronic psychological stress is an emerging public health issue. In the United States, around $\$ 150$ billion of revenue is lost annually due to stress-related behaviours, such as low productivity, absenteeism, poor decision making, stress-induced mental illness, and substance abuse [4]. Besides, chronic psychological stress is a risk factor for various health conditions, such as heart diseases, asthma, obesity and diabetes [3]. This review will focus on the effects of chronic psychological stress on bone health.

Affective disorders are the sequela of chronic psychological stress. Many studies have reported the association between affective disorders and bone health. Schweiger et al. first discovered the relationship between depression and osteoporosis, suggesting that affective disorders are associated with bone loss [5]. Since then, the association between 
affective disorders and osteoporosis continues to be examined. Two meta-analyses have demonstrated that depression is associated with decreased bone mineral density (BMD) and increased fracture risk [6, 7]. Catalano et al. reported that postmenopausal women with higher anxiety scores have lower BMD T-score [8]. Populations with post-traumatic stress disorder also have a higher risk of developing osteoporosis in a longitudinal study [9]. However, studies on the relationship between chronic psychological stress and osteoporosis remain limited [10]. This gap is probably due to the assumption that these affective disorders are an extension of excessive psychological stress. However, individuals without affective disorders also experience psychological stress. Erez et al. found that even though the strength of the association between perceived stress and BMD is lower compared to depression in postmenopausal women, psychological stress still affects their bone health significantly [11].

Several studies have demonstrated that psychological stress is associated with osteoporosis [12-16]. Fink et al. demonstrated that the number of stressful life events correlated positively with the risk of concurrent accelerated hip bone loss in older men [15]. Besides, osteoporosis was found to be prevalent among UK veterans who participated in the Gulf War, probably due to chronic stress, including behavioural changes due to psychological stress during or after the war [17]. Pedersen et al. also reported a positive association between the risk of osteoporotic fracture and perceived stress [18]. Hahn et al. reported that lower BMD at the lumbar spine, femoral neck, and total femur was associated with moderate to severe perceived stress in men, but not for premenopausal or postmenopausal women [13]. Given the existing evidence, one would ask how psychological stress induces bone loss. This review attempts to answer this question by providing a brief overview of the possible mechanisms involved.

\section{Factors mediating the relationship between psychological stress and osteoporosis}

Psychological stress impacts bone health adversely through two prominent mechanisms, i.e. physiological changes and the attainment of unhealthy behaviours. It is important to note that the mechanisms discussed in this review affect the skeletal system inter-dependently, and their interactions should not be neglected.

\section{Physiological factors}

Bone loss occurs due to the imbalance in bone remodelling when the rate of osteoclast-mediated bone resorption exceeds osteoblast-mediated bone formation. The bone remodelling process is mediated by the receptor activator of nuclear factor kappa-B (RANK)/RANK ligand (RANKL)/osteoprotegerin (OPG) axis. RANKL released by the osteoblast lineage cells binds to its receptor, RANK, on the osteoclast precursor cells. The RANK-RANKL binding then stimulates the differentiation of osteoclast precursor cells into preosteoclasts, which fuse to form mature, multinucleated osteoclasts. Osteoblasts also secrete OPG, a decoy receptor for RANKL, which inhibits RANK-RANKL interaction and thus reduces osteoclastogenesis. Therefore, the ratio of RANK and OPG is indicative of the bone resorption rate [19].

Psychological stress is associated with the dysregulation of the endocrine system. Hypersecretion of cortisol, a key feature in chronic psychological stress, occurs due to dysregulation of the hypothalamus-pituitary-adrenal (HPA) axis [20-22]. Cortisol binds to the glucocorticoid receptor, which undergoes conformational changes and translocates rapidly to the nucleus to bind to glucocorticoid response element and stimulate transcription of certain genes [23]. Cortisol upregulates RANKL [24] and downregulates OPG expressions in osteoblasts [24-27]. In murine cell culture studies, cortisol dose-dependently impairs osteoclastogenesis and osteoblastogenesis, and increases osteoblast and osteocyte apoptosis in cortical bone [28]. In contrast, glucocorticoids promote the survival of osteoclasts [29]. Overall, the increased glucocorticoid level may lead to negative bone turnover and subsequently bone loss. This mechanism explains the report of Henneicke et al., whereby even chronic mild stress upregulates glucocorticoid signalling, which subsequently causes bone loss, in a site- and gender-specific manner [14].

Furthermore, studies have shown that sustained psychological stress may originate from a pronounced and enduring hyperactivation of the sympathetic nervous system [30]. Osteoblasts and osteoclasts possess receptors for neuropeptides and noradrenaline [31], implying the direct role of the sympathetic nervous system in bone homeostasis. Yirmiiya et al. demonstrated that stress-induced bone loss was associated with an elevated noradrenaline level in bone. They also reported that propranolol, a $\beta$-adregenic antagonist, may ameliorate stresstriggered osteoporosis. These observations suggest that hyperactivation of the adrenergic system might mediate the relationship between stress and bone loss [32]. The level of neuropeptide $Y$, another neurotransmitter of the sympathetic nervous system, is reported to increase during mental stress and is associated with resilience to stress [33]. 
Overexpression of neuropeptide $\mathrm{Y}$ inhibits bone formation and enhances bone loss [34]. The action of neuropeptide $\mathrm{Y}$ on bone is mediated by hypothalamic Y1 and osteoblastic Y2 receptors [35]. Neuromedin U is another neuropeptide synthesised in the hypothalamus, pituitary and small intestine, and is associated positively with stress behaviour and stress-related hormones in preclinical studies [36]. Neuromedin U knocked-out mice were found to have increased bone mass due to increased bone formation. Further studies showed that neuromedin acted on bone cells through central nervous system but not directly [37]. These neuropeptides may work together during chronic stress to induce bone loss.

Inflammation is one of the important secondary risk factors for osteoporosis, as observed in various inflammatory conditions [38, 39]. Chronic psychological stress, as observed in the caregivers of ill patients, is associated with increased pro-inflammatory markers (PICs) [40]. In preclinical studies, excessive inflammation of the brain impairs memory and learning, and induces depressive symptoms [41-43]. Although both acute and chronic psychological stress are associated with increased in PICs [44, 45], prolonged exposure to PICs as in chronic stress poses a greater risk to health, including bone health. In bone remodelling, PICs promote RANK expression on monocytes, increase RANKL but reduce the production of OPG by osteoblast lineage cells, thereby increasing osteoclast formation $[19,46-49]$. In particular, tumour necrosis alpha-a is a more potent osteoclastogenic factor than the other PICs since it can amplify RANKL signalling in osteoclasts $[19,46-48]$, thereby enhancing osteoclastogenesis and bone resorption. Thus, low-grade chronic inflammation induced by chronic psychological stress might induce bone loss through increased bone resorption.

Many hormones secreted by the pituitary have direct and indirect actions on bone health [50]. Prolactin is a pleiotropic peptide hormone produced by the lactotrophs in the anterior pituitary [51]. Its primary function is to initiate and maintain lactation, but it also plays a significant role in stress response. Prolactin can stimulate the synthesis of catecholamines and sensitise the HPA axis [52]. A wide range of different stressors, including ether [53], restraint [54-56], foot shock [57, 58] and noise [59], has been shown to elevate circulating prolactin levels in preclinical models. Osteoblasts but not osteoclasts express prolactin receptors [60]. Prolactin exposure upregulates secretion of PICs (e.g. tumour necrosis factor- $\alpha$ and interleukin (IL)-1) in the osteoblasts and increases RANKL/OPG ratio, thereby favouring osteoclast formation and bone resorption [61, 62]. The bone formation markers reduce in pups exposed to high prolactin level [63]. However, in another study using co-culture of synovial fibroblasts and osteoclast progenitors, prolactin suppressed the formation of mature osteoclasts by inhibiting the secretion of RANKL by synovial fibroblasts [64]. Thus, the effects of prolactin on osteoclast differentiation might depend on the adjacent cell types. On the other hand, increased prolactin level is associated with reduced BMD in humans $[65,66]$. Therefore, further studies are required to delineate the associations between psychological stress, prolactin level and bone health.

Variation in the lipophilic sex hormones that could penetrate the blood-brain barrier is suggested to affect the stress response of the brain. Women between puberty and menopause generally show lower HPA and autonomic axis activation during psychological stress than men, but the difference diminishes after menopause [67]. Oestrogen supplementation after menopause attenuates HPA response of women during stress test [68]. Despite this, Study of Women's Health across the Nation did not observe a significant increase in perceived stress and depressive symptoms during the menopausal transition [69, 70]. However, Seattle Midlife Women's Health Study observed a significant increase in women's overnight cortisol levels during the menopausal transition, and the cortisol correlated significantly with sex hormones [71]. On the other hand, menopause in women and testosterone deficiency syndrome in men are known risk factors for osteoporosis [72, 73]. Gonadal hormones are essential in the maintenance of bone mass [74]. Both oestrogen and testosterone play distinct roles in bone homeostasis in both sexes, and their actions are site-specific. In both men and women, oestrogen maintains $80 \%$ of the cortical bone mass. In women, oestrogen is the primary regulatory hormone of bone homeostasis for cancellous bone, while in men, testosterone maintains the cancellous bone mass [74]. Oestrogens suppress osteoblast apoptosis and improve osteoblast survival. They also inhibit osteoclastogenesis by reducing serum RANKL level and promote osteoblastic production of OPG. Oestrogens also induce the production of Wnt/Bcatenin, which promotes osteoblast maturation and increases OPG production through increasing transforming growth factor- $\beta$ [74]. Meanwhile, some actions of testosterone on bone health are attributed to its conversion to oestrogens by the aromatase enzymes [73, 75]. Chronic stress reduces the serum level of both testosterone and oestrogen [76, 77]. Thus, a reduction in gonadal hormones is partially responsible for psychological stress-induced bone loss. 


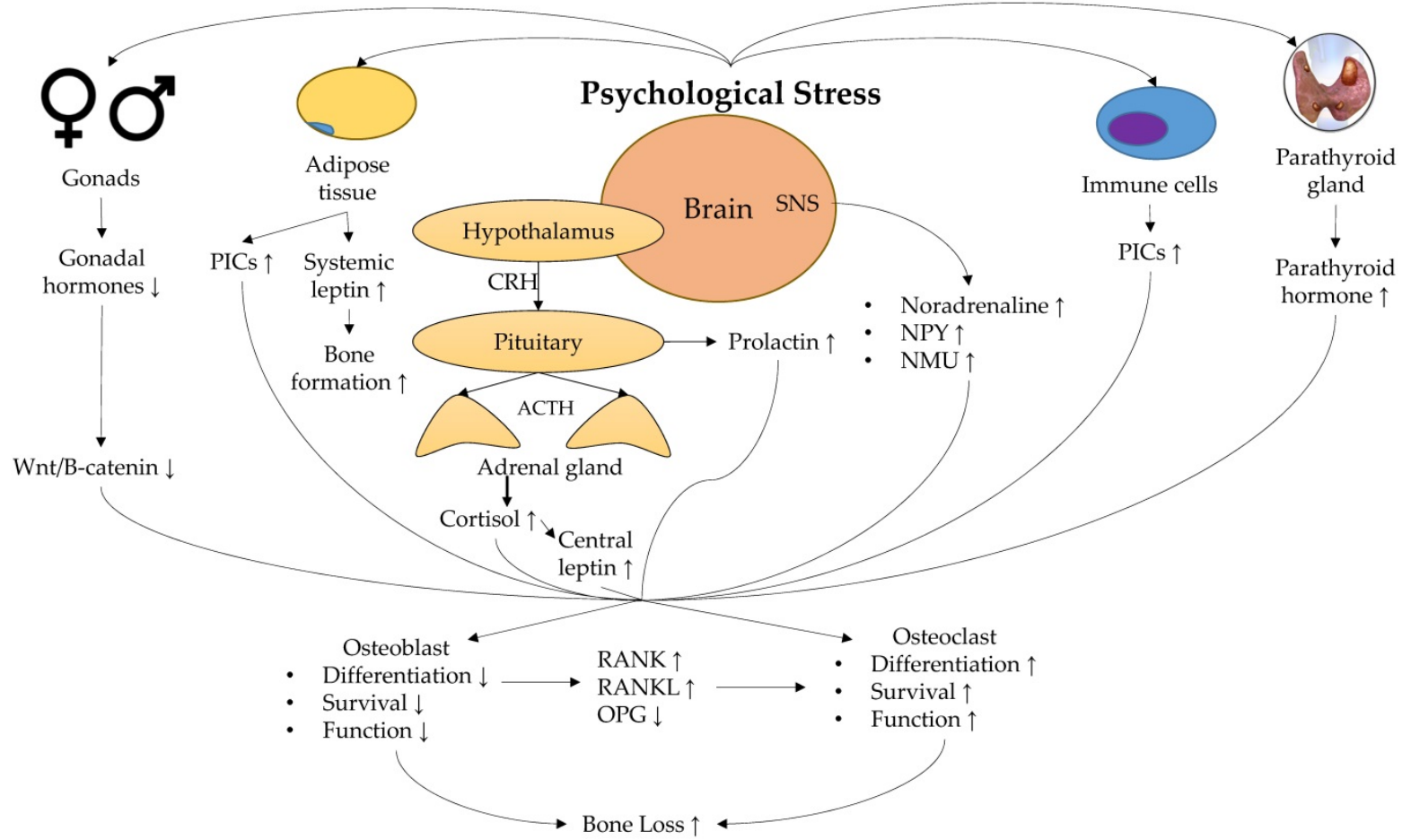

Figure 1. Physiological mechanisms linking stress and low bone mineral density. Abbreviation: ACTH, adrenocorticotropic hormone; CRH, corticotropin; NMU, neuromedin U; NPY, neuropeptide Y; OPG, osteoprotegerin; PICs, pro-inflammatory cytokines; RANK, receptor activator of nuclear factor kappa-B; RANKL, receptor activator of nuclear factor kappa-B ligand; SNS, sympathetic nervous system.

Leptin is a peptide hormone synthesised by adipocytes to regulate food intake via the hypothalamus. Psychological stress-induced elevation in cortisol level increases the leptin level by stimulating leptin resistance [78, 79], though this action may be sex-dependent [80]. Studies suggested a complex role of leptin in regulating bone remodelling. Leptin and leptin receptor-deficient hypogonadal mice showed increased trabecular bone volume at the spine but reduced bone mass at the femur [81-83]. Intracerebroventricular infusion of leptin in wildtype mice and ewes reduced trabecular bone volume [83, 84]. Takeda et al. demonstrated that antiosteogenic action of leptin was inhibited by gold thioglucose, which distorts the structure of ventromedial hypothalamic nucleus, demonstrating the involvement of the central nervous system in the action of leptin [85]. Thus, increased leptin level during chronic stress could reduce bone mass through the central nervous system. On the other hand, systemic infusion of leptin generally protects against bone loss in animal models of osteoporosis [86-88]. This observation probably explains the bone protective effects of obesity apart from increased mechanical loading since leptin level increases with increased fat mass. Therefore, the net skeletal effects of leptin during chronic psychological stress depend on the balance between the direct effects of leptin and its indirect effects through the central nervous system.

Parathyroid hormone (PTH) is an essential regulator and minute-to-minute determinant of both extracellular and intracellular calcium homeostasis in the blood [89]. Using a murine model of restraint stress, Terzioqlu et al. demonstrated that psychological stress increases plasma PTH level by upregulating the calcium-sensing receptor on the chief cells in the parathyroid glands [90]. The actions of PTH in the body are bi-directional [91]. While intermittent exposure to higher than average PTH concentration exerts anabolic effects on the bone, sustained exposure to high PTH concentration can upregulate RANKL expression and inhibit OPG expression by the osteoblasts [92, 93]. Therefore, sustained chronic stress may enhance bone loss via enduring, increased PTH concentration.

A summary of the physiological response towards psychological stress and its effect on bone is shown in Figure 1.

\section{Behavioural factors}

In the basic stress model, stress can stimulate psychological (e.g. anxiety) and physical reaction (e.g. increased blood pressure) reactions, causing an individual to implement certain health behaviours to attenuate the reactions [94]. Some of the common stress-coping behaviours include unhealthy eating habits [95], alcohol drinking [96] and cigarette smoking [97]. In the Korea National Health and Nutrition Examination Survey (2007-2012), high calorie and alcohol intake, as well as cigarette 
smoking were associated with psychological stress and distress in both men and women [98].

Psychological stress has been proposed as a factor for smoking initiation and relapse, especially among women [99]. Increasing stress due to income was associated with nicotine dependence in the lower-income group of Pennsylvania Adult Smoking Study [100]. Despite some conflicting findings, smoking is generally agreed as a risk factor of osteoporosis [101]. Nicotine, as the principal active ingredient in tobacco smoke [102], is reported to exert dual effects on osteoblast proliferation and function [103]. Low-dose nicotine increases human mesenchymal stem cells proliferation and differentiation to osteoblasts, but high dose inhibits both processes [104]. Nicotine also increases promote the secretion of PICs from osteoblast cultures [105], and in animal models [106]. Of note, nicotine upregulates osteoblastic tumour necrosis alpha-a expression [105], which acts synergistically with RANKL to promote osteoclast formation [107]. Non-toxic doses of nicotine could increase bone resorption activity of porcine osteoclasts in culture directly [108]. In non-osteoblast suppressive doses, nicotine and cotinine (a metabolite of nicotine) inhibit catalase and glutathione reductase activity, leading to accumulation of ROS [109]. Nicotine also suppresses sirtuin 3-mitochondrial superoxide dismutase 2 axis, leading to mitochondrial oxidative damage in osteoblasts [110]. Apart from nicotine, tobacco smoke contains other chemicals. Exposure of mesenchymal stem/stromal cells to tobacco smoke suppresses osteogenic differentiation by increasing superoxide radicals and depleting intracellular glutathione [109].

Cigarette smoking is also associated with changes in hormone levels. Smoking status indicated by cotinine level has been associated negatively with thyroid-stimulating hormone level, but the relationship with thyroid hormones is not certain (triiodothyronine and thyroxine) [111, 112]. TSH is associated with increased bone mass independent of triiodothyronine and thyroxine levels [113], so the decrease might impact bone health. However, a meta-analysis showed that smoking increased the risk of Graves' disease [114]. Overt thyroid toxicosis is known to reduce bone mass through high remodelling [115]. Smoking is also associated with higher cortisol in the morning and throughout the day in a cohort of elderly [116]. The adverse effects of cortisol on bone have been elaborated earlier. In the Tromsø Study, higher serum PTH, lower vitamin D and calcium absorption were reported among smokers than the non-smokers of both sexes [117]. Reduce calcium absorption will cause the body to mobilise the calcium reserve in the bone, resulting in bone loss. Lastly, smoking is associated with lower androgen levels in men [118], lower ovarian hormones in women with regular menses [119], and higher sex hormones in postmenopausal women [120]. Therefore, the impact of smoking on bone mediated by sex hormones may depend on sex and menstrual status.

Perceived psychological stress has been associated with alternation of dietary habits. In a study involving Korean university students, higher perceived stress was associated with less frequent fruit and vegetable intake in both sexes and lower subjective judgement of healthy eating. Stress-related decrease eating was also apparent in these subjects [121]. Similarly, higher perceived stress was associated with increased past-week soda, coffee, energy drink, salty snack, frozen food, and fast food consumption in Caucasian university students [122]. In a study among Puerto Rican adults living in Boston, higher perceived stress predicted less fruit, vegetable and protein intake, but higher salty snacks [123]. Prolonged practice of unhealthy dietary trend will have an impact on bone health. Higher fruit and vegetable intakes have been associated with increased BMD and reduced fracture risk [124, 125]. This association could be mediated by the presence of vitamins and polyphenols in fruits and vegetables [126], as well as basic effects of the diet [127], which are beneficial to bone health. Vitamins and polyphenols act as antioxidants and anti-inflammatory agents, which promote osteoblasts survival and suppress osteoclast formation through mechanisms described in the earlier sections. High dietary salt intake is known to cause hypertension and increase urinary calcium excretion [128]. A recent preclinical study also found that high salt intake caused induction of T-helper 17 cells and suppression of T-regulatory cells. The altered T-cell population led to increased PIC and reduced anti-inflammatory cytokine levels, in conjunction with the destruction of bone microstructure of mice on high salt intake [129].

On the other hand, psychological stress can lead to either reduced or overeating [121, 122]. Long-term change of appetite could alter body weight. Multiple studies show that body weight is directly proportional to BMD [130], possibly via increasing mechanical loading of the body and synthesis of oestrogen by the adipose cells, which subsequently stimulate osteoblast activity [7]. At the same time, adipose tissue is a source of PICs, which are detrimental to bone health [131]. However, the association between chronic stress and body mass index remains unclear and confounded by age, gender, and race [132]. In contrast, centralised obesity measured by waist-to-hip ratio shows a more 
consistent association with chronic stress [133]. Centralised obesity is associated with activation of the HPA axis and dysregulation of the sympathetic nervous system, which results in bone loss [134]. Thus, while increased BMI protects against bone loss, centralised obesity associated with psychological stress is detrimental to bone health. Underweight is consistently reported as a risk factor for osteoporosis due to reduced mechanical loading and malnutrition [135].

Alcoholism is prevalent among individuals with chronic stress due to the stress-relieving properties of alcohol. On the other hand, chronic alcohol use leads to altered stress-adaptive responses, triggering relapse and forms a vicious stress-alcohol use cycle [136]. Heavy consumption of alcohol is detrimental to health, including that of the skeletal system [137]. Alcohol affects bone health via many mechanisms, both direct and indirect [138, 139]. Firstly, alcohol downregulates the expression of insulin-like growth factor [140], which enhances osteoblast maturation and proliferation [141]. Secondly, chronic binge intake of alcohol upregulates the expression of PICs that stimulate bone resorption [142-144]. Thirdly, the level of circulating sclerostin secreted by osteocytes was reported to be higher in alcoholics [145]. Sclerostin inhibits Wnt signalling that regulates the osteoblast function, differentiation and survival, leading to decreased bone formation [145, 146]. Fourthly, ethanol exposure upregulates the expression of NADPH oxidase enzymes that generate reactive oxygen species [147]. These free radicals can enhance RANKL expression [148]. Other adverse effects of alcoholism include decreased production of the gonadal hormones [149-151], decreased vitamin D level, which results in malabsorption of calcium, [139] and centralised obesity [152]. All of these adverse effects can give rise to bone loss.

Psychological stress is associated with sedentary lifestyles [153], which in turns, are linked with low BMD [154, 155]. Moreover, physical inactivity is associated with centralised obesity [156]. This observation suggests that physical inactivity is one of the underlying mechanisms between psychological stress and low BMD. Physical activities have an important role in ameliorating chronic stress [157] and osteoporosis [158].

The overall effects of stress-induced behaviours on bone heath are presented in Figure 2 .

\section{Epigenetic basis for the relationship between psychological stress and bone health}

Epigenetic factors like DNA methylation also influence the development of skeletal diseases [159].
Prenatal exposure of glucocorticoids induced by psychological stress could be responsible for epigenetic regulation of bone health. Prolonged glucocorticoid exposure in pregnant animals reduced mRNA expression of placental $11 \beta$-hydroxysteroid dehydrogenase-2 [160], which regulates intrauterine exposure of the foetus to glucocorticoids. Restraininduced stress in dams led to downregulation of gene expression of $11 \beta$-hydroxysteroid dehydrogenase- 2 in the placenta, and altered gene expression of DNA methyltransferase of the brain in the foetus [161]. Increased plasma corticosterone induced by diet restriction in dams also downregulated placental $11 \beta$ hydroxysteroid dehydrogenase- 2 and transplacental exposure of the foetus to glucocorticoids. The alteration of HPA axis of the offspring is dependent on life stages, i.e. it decreases at weaning, changes marginally at young adulthood and is chronically hyperactivated at old age [162]. These changes could alter skeletal development trajectory, but not many studies are available in the literature. In an animal study, mouse offspring born to dams subjected to restrain stress during pregnancy experienced increased corticosterone level, higher bone resorption, lower bone formation and significant deterioration of vertebral and femoral microstructures in adulthood [163]. However, the epigenetic basis of these changes is not studied in detail. It should be noted that in animal models of stress, physical stressors (like restraint stress) is used, which may not represent the complexity of human psychological stress. Understanding the epigenetic regulation of chronic stress on the skeletal system is important, so that steps to protect bone health can be initiated in utero.

\section{Socioeconomic status and osteoporosis: is psychological stress a mediator?}

The effects of psychological stress may provide a biological explanation of the relationship between socioeconomic status and bone health. A low economic status could lead to poor residential condition, community hazards, suboptimal access to medical support and malnutrition, which causes psychological stress and harms the general well-being of a person [164]. Indices of socioeconomic status, such as household income [165], education level [72], living condition [166], have been associated with variation of BMD. A systematic review suggested a strong relationship between living with others and reduced risk of osteoporotic fracture, while evidence for income and education level is conflicting [167]. Early-life exposure to income equality predicted life dissatisfaction and psychomotor symptoms among adolescents, especially among females [168]. Whether this stress related to socioeconomic status is partially 
responsible for a higher uptake of behaviours detrimental to bone health among adolescents from lower socioeconomic, such as smoking and alcohol [169, 170], deserve further study. However, direct evidence proving the role of psychological stress as a mediator in the relationship between bone health and socioeconomic status is limited and should be validated in future studies.

\section{Conclusion}

Psychological stress gives rise to complex physiological and behavioural changes which could affect bone health. These factors interact with each other to alter bone remodelling, resulting in a net bone loss (Figure 3). More comprehensive and well-planned epidemiological studies are needed to investigate the causal relationship between psychological stress and BMD or fracture. Future studies should take into consideration changes in biomarkers of inflammation, oxidative stress, hormones and neurotransmitters, to establish the relationship between psychological stress and bone health. The difference in the effects of acute/chronic stress, mild/moderate/chronic stress on the severity of bone loss should also be investigated. Lastly, stress management strategies should consider the multidimensional effects of health. Effective stress management should incorporate counselling and lifestyle interventions to prevent psychological stress to progress into affective disorders, and its related complications on other biological systems. For example, moderate exercise could have a positive impact in relieving psychological stress and improving bone health. A balanced and healthy diet will attenuate the enhancer of psychological stress such as neuroinflammation and oxidative stress, and promote optimal bone health.

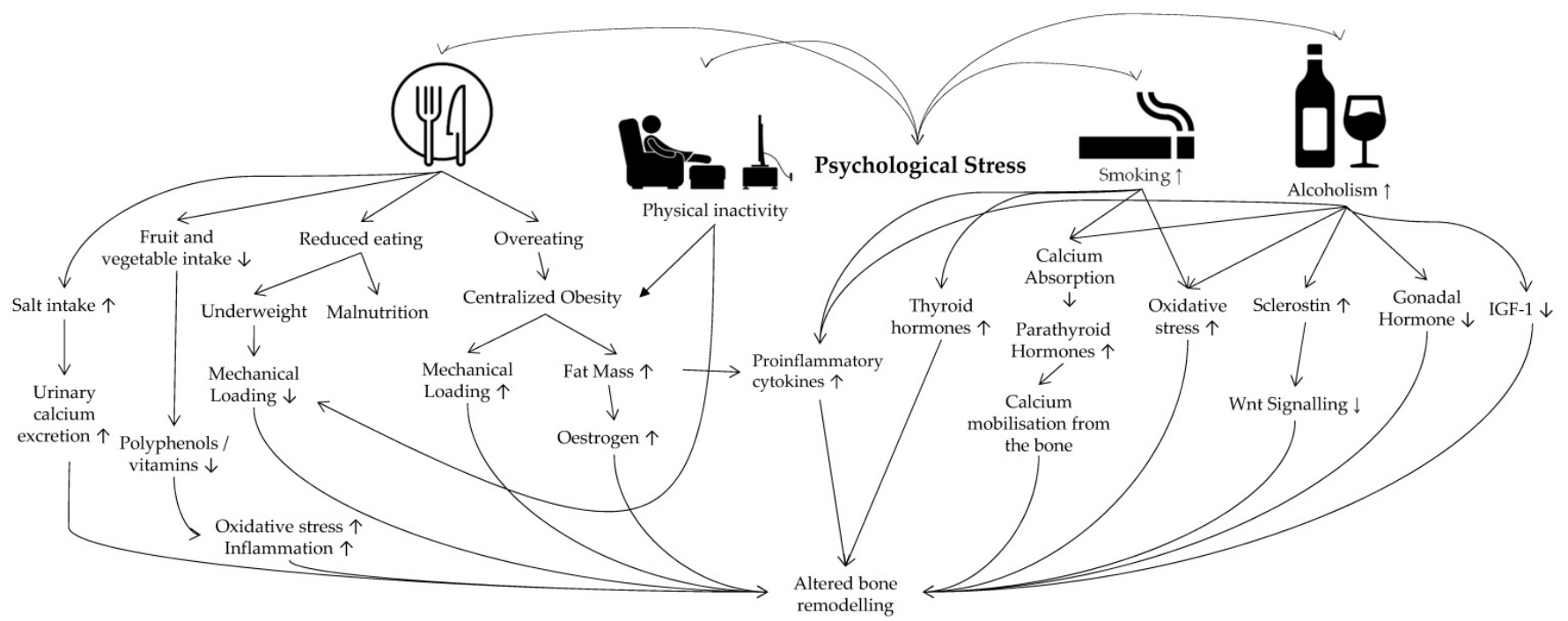

Figure 2. Behavioural factors linking psychological stress and osteoporosis. Abbreviation: IGF-1 insulin-like growth factors-1.

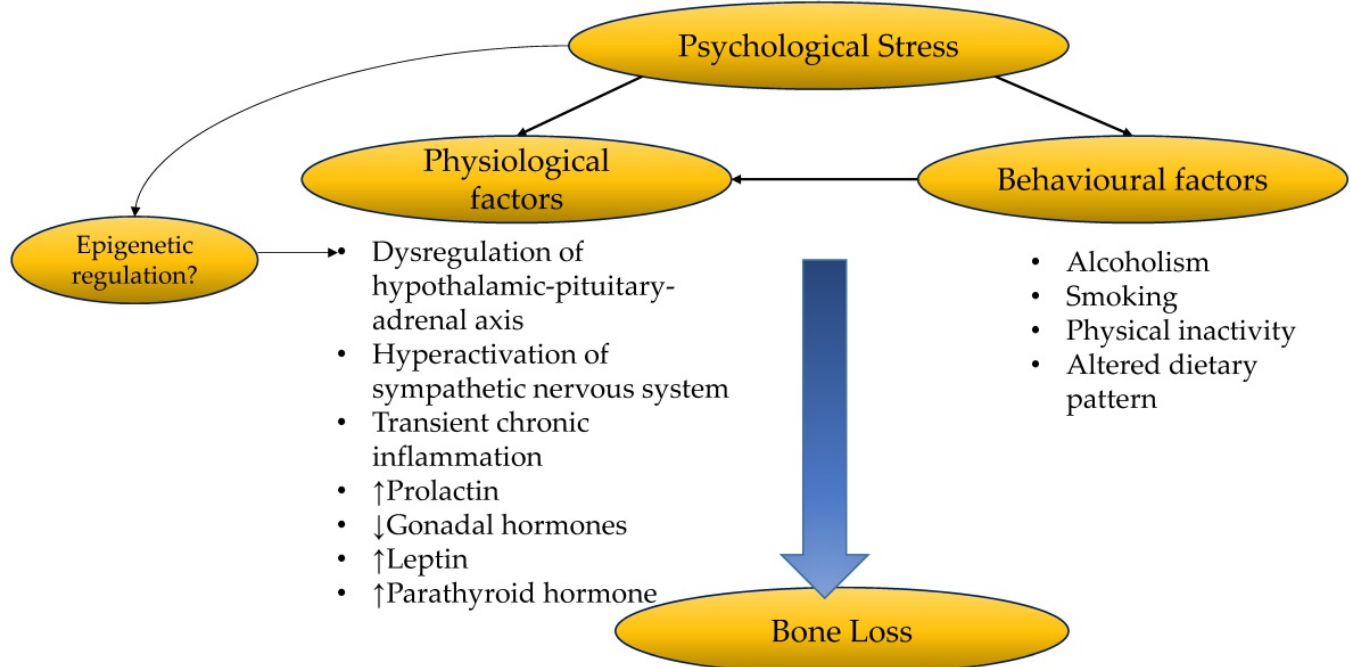

Figure 3. The relationship between psychological stress and bone health. 


\section{Acknowledgements}

the funding.

\section{Author Contributions}

Conceptualisation, J.-S.N. and K.-Y.C.; literature search, J.-S.N. and K.-Y.C.; writing-original draft preparation, J.-S.N.; writing-review and editing, K.-Y.C.; visualisation, J.-S.N. and K.-Y.C.; supervision, K.-Y.C.; project administration, K.-Y.C.; funding acquisition, K.-Y.C. All authors have read and agreed to the published version of the manuscript.

\section{Funding}

Universiti Kebangsaan Malaysia funds the researchers through Fundamental Research Grant (FF-2018-405).

\section{Competing Interests}

The authors have declared that no competing interest exists.

\section{References}

1. Johnell O, Kanis JA. An estimate of the worldwide prevalence and disability associated with osteoporotic fractures. Osteoporos Int. 2006; 17: 1726-33.

2. International Osteoprorosis Foundation. Broken Bones, Broken Lives: A roadmap to solve the fragility fracture crisis in Europe. Nyon: International Osteoprorosis Foundation; 2018.

3. Cohen S, Janicki-Deverts D, Miller GE. Psychological Stress and Disease. JAMA. 2007; 298: 1685-7.

4. Tang TL-P, Hammontree ML. The Effects of Hardiness, Police Stress, and Life Stress on Police Officers' Illness and Absenteeism. Public Pers Manage. 1992; 21: $493-510$

5. Schweiger U, Deuschle M, Korner A, Lammers CH, Schmider J, Gotthardt U, et al. Low lumbar bone mineral density in patients with major depression. Am J Psychiatry. 1994; 151: 1691-3.

6. Wu Q, Magnus JH, Liu J, Bencaz AF, Hentz JG. Depression and low bone mineral density: a meta-analysis of epidemiologic studies. Osteoporos Int. 2009; 20: 1309-20.

7. Mezuk B, Eaton WW, Golden SH. Depression and osteoporosis: epidemiology and potential mediating pathways. Osteoporos Int. 2008; 19: 1-12.

8. Catalano A, Martino G, Bellone F, Gaudio A, Lasco C, Langher V, et al. Anxiety levels predict fracture risk in postmenopausal women assessed for osteoporosis. Menopause. 2018; 25: 1110-5.

9. Huang WS, Hsu JW, Huang KL, Bai YM, Su TP, Li CT, et al. Post-traumatic stress disorder and risk of osteoporosis: A nationwide longitudinal study. Stress Health. 2018; 34: 440-5

10. Kelly RR, McDonald LT, Jensen NR, Sidles SJ, LaRue AC. Impacts of Psychological Stress on Osteoporosis: Clinical Implications and Treatment Interactions. Front Psychiatry. 2019; 10: 200.

11. Erez HB, Weller A, Vaisman N, Kreitler S. The relationship of depression, anxiety and stress with low bone mineral density in post-menopausal women. Arch Osteoporos. 2012; 7: 247-55.

12. Foertsch S, Haffner-Luntzer M, Kroner J, Gross F, Kaiser K, Erber M, et al. Chronic psychosocial stress disturbs long-bone growth in adolescent mice. Dis Model Mech. 2017; 10: 1399-409.

13. Hahn $\mathrm{C}, \mathrm{Oh} \mathrm{JH}$, Joo SH, Jeong JE, Chae JH, Lee CU, et al. Association between mental health status and bone mineral density: Analysis of the 2008-2010 Korea national health and nutrition examination survey. PLoS One. 2017; 12: e0187425.

14. Henneicke H, Li J, Kim S, Gasparini SJ, Seibel MJ, Zhou H. Chronic Mild Stress Causes Bone Loss via an Osteoblast-Specific Glucocorticoid-Dependent Mechanism. Endocrinology. 2017; 158: 1939-50

15. Fink HA, Kuskowski MA, Cauley JA, Taylor BC, Schousboe JT, Cawthon PM, et al. Association of stressful life events with accelerated bone loss in older men: the osteoporotic fractures in men (MrOS) study. Osteoporos Int. 2014; 25 : 2833-9.

16. Seferos N, Kotsiou A, Petsaros S, Rallis G, Tesseromatis C. Mandibular bone density and calcium content affected by different kind of stress in mice. J Musculoskelet Neuronal Interact. 2010; 10: 231-6.
17. Compston JE, Vedi S, Stephen AB, Bord S, Lyons AR, Hodges SJ, et al. Reduced bone formation in UK Gulf War veterans: a bone histomorphometric study. J Clin Pathol. 2002; 55: 897-9.

18. Pedersen AB, Baggesen LM, Ehrenstein V, Pedersen L, Lasgaard M, Mikkelsen EM. Perceived stress and risk of any osteoporotic fracture. Osteoporos Int. 2016; 27: 2035-45.

19. Weitzmann MN. Bone and the Immune System. Toxicol Pathol. 2017; 45: 911-24.

20. Gold PW, Loriaux DL, Roy A, Kling MA, Calabrese JR, Kellner CH, et al. Responses to corticotropin-releasing hormone in the hypercortisolism of depression and Cushing's disease. Pathophysiologic and diagnostic implications. N Engl J Med. 1986; 314: 1329-35.

21. Holsboer F. Prediction of clinical course by dexamethasone suppression test (DST) response in depressed patients - physiological and clinical construct validity of the DST. Pharmacopsychiatria. 1983; 16: 186-91.

22. Nemeroff CB, Widerlov E, Bissette G, Walleus H, Karlsson I, Eklund K, et al. Elevated concentrations of CSF corticotropin-releasing factor-like immunoreactivity in depressed patients. Science. 1984; 226: 1342-4.

23. Ramamoorthy S, Cidlowski JA. Corticosteroids: Mechanisms of Action in Health and Disease. Rheum Dis Clin North Am. 2016; 42: 15-vii.

24. Swanson $C$, Lorentzon $M$, Conaway $\mathrm{HH}$, Lerner $\mathrm{UH}$. Glucocorticoid regulation of osteoclast differentiation and expression of receptor activator of nuclear factor-kappaB (NF-kappaB) ligand, osteoprotegerin, and receptor activator of NF-kappaB in mouse calvarial bones. Endocrinology. 2006; 147: 3613-22.

25. Brandstrom $\mathrm{H}$, Bjorkman $\mathrm{T}$, Ljunggren $\mathrm{O}$. Regulation of osteoprotegerin secretion from primary cultures of human bone marrow stromal cells. Biochem Biophys Res Commun. 2001; 280: 831-5.

26. Hofbauer LC, Gori F, Riggs BL, Lacey DL, Dunstan CR, Spelsberg TC, et al. Stimulation of osteoprotegerin ligand and inhibition of osteoprotegerin production by glucocorticoids in human osteoblastic lineage cells: potential paracrine mechanisms of glucocorticoid-induced osteoporosis. Endocrinology. 1999; 140: 4382-9.

27. Vidal NO, Brandstrom $\mathrm{H}$, Jonsson $\mathrm{KB}$, Ohlsson C. Osteoprotegerin mRNA is expressed in primary human osteoblast-like cells: down-regulation by glucocorticoids. J Endocrinol. 1998; 159: 191-5.

28. Weinstein RS, Jilka RL, Parfitt AM, Manolagas SC. Inhibition of osteoblastogenesis and promotion of apoptosis of osteoblasts and osteocytes by glucocorticoids. Potential mechanisms of their deleterious effects on bone. J Clin Invest. 1998; 102: 274-82.

29. Jia D, O'Brien CA, Stewart SA, Manolagas SC, Weinstein RS. Glucocorticoids act directly on osteoclasts to increase their life span and reduce bone density. Endocrinology. 2006; 147: 5592-9.

30. Wong ML, Kling MA, Munson PJ, Listwak S, Licinio J, Prolo P, et al. Pronounced and sustained central hypernoradrenergic function in major depression with melancholic features: relation to hypercortisolism and corticotropin-releasing hormone. Proc Natl Acad Sci U S A. 2000; 97: 325-30.

31. Togari A Adrenergic regulation of bone metabolism: possible involvement of sympathetic innervation of osteoblastic and osteoclastic cells. Microsc Res Tech. 2002; 58: 77-84

32. Yirmiya R, Goshen I, Bajayo A, Kreisel T, Feldman S, Tam J, et al. Depression induces bone loss through stimulation of the sympathetic nervous system. Proc Natl Acad Sci U S A. 2006; 103: 16876-81.

33. Morales-Medina JC, Dumont Y, Quirion R. A possible role of neuropeptide $Y$ in depression and stress. Brain Research. 2010; 1314: 194-205.

34. Franquinho F, Liz MA, Nunes AF, Neto E, Lamghari M, Sousa MM. Neuropeptide $\mathrm{Y}$ and osteoblast differentiation--the balance between the neuro-osteogenic network and local control. Febs j. 2010; 277: 3664-74.

35. Lee NJ, Herzog H. NPY regulation of bone remodelling. Neuropeptides. 2009; 43: 457-63.

36. Martinez VG, O'Driscoll L. Neuromedin U: A Multifunctional Neuropeptide with Pleiotropic Roles. Clinical Chemistry. 2015; 61: 471-82.

37. Sato S, Hanada R, Kimura A, Abe T, Matsumoto T, Iwasaki M, et al. Central control of bone remodeling by neuromedin U. Nat Med. 2007; 13: 1234-40.

38. Ginaldi L, Di Benedetto MC, De Martinis M. Osteoporosis, inflammation and ageing. Immun Ageing. 2005; 2: 14-

39. Mohamad NV, Soelaiman IN, Chin KY. Are Oxidative Stress and Inflammation Mediators of Bone Loss due to Estrogen Deficiency? A Review of Current Evidence. Endocr Metab Immune Disord Drug Targets. 2020; 20: $1478-87$.

40. von Känel R, Mills PJ, Mausbach BT, Dimsdale JE, Patterson TL, Ziegler MG, et al. Effect of Alzheimer caregiving on circulating levels of C-reactive protein and other biomarkers relevant to cardiovascular disease risk: a longitudinal study. Gerontology. 2012; 58: 354-65.

41. Miller AH, Maletic V, Raison CL. Inflammation and its discontents: the role of cytokines in the pathophysiology of major depression. Biol Psychiatry. 2009; 65: $732-41$

42. McAfoose J, Baune BT. Evidence for a cytokine model of cognitive function. Neurosci Biobehav Rev. 2009; 33: 355-66.

43. Dantzer R, O'Connor JC, Freund GG, Johnson RW, Kelley KW. From inflammation to sickness and depression: when the immune system subjugates the brain. Nat Rev Neurosci. 2008; 9: 46-56.

44. Marsland AL, Walsh C, Lockwood K, John-Henderson NA. The effects of acute psychological stress on circulating and stimulated inflammatory 
markers: A systematic review and meta-analysis. Brain Behav Immun. 2017; 64: 208-19.

45. Potier F, Degryse J-M, de Saint-Hubert M. Impact of caregiving for older people and pro-inflammatory biomarkers among caregivers: a systematic review. Aging Clin Exp Res. 2018; 30: 119-32.

46. Zhang YH, Heulsmann A, Tondravi MM, Mukherjee A, Abu-Amer Y. Tumor necrosis factor-alpha (TNF) stimulates RANKL-induced osteoclastogenesis via coupling of TNF type 1 receptor and RANK signaling pathways. J Biol Chem. 2001; 276: 563-8.

47. Lam J, Takeshita S, Barker JE, Kanagawa O, Ross FP, Teitelbaum SL. TNF-alpha induces osteoclastogenesis by direct stimulation of macrophages exposed to permissive levels of RANK ligand. J Clin Invest. 2000; 106: 1481-8.

48. Fuller K, Murphy C, Kirstein B, Fox SW, Chambers TJ. TNFalpha potently activates osteoclasts, through a direct action independent of and strongly synergistic with RANKL. Endocrinology. 2002; 143: 1108-18.

49. Ostrowska Z, Ziora K, Oswiecimska J, Marek B, Swietochowska E, Kajdaniuk $\mathrm{D}$, et al. Selected pro-inflammatory cytokines, bone metabolism, osteoprotegerin, and receptor activator of nuclear factor- $\mathrm{kB}$ ligand in girls with anorexia nervosa. Endokrynol Pol. 2015; 66: 313-21.

50. Mazziotti G, Frara S, Giustina A. Pituitary Diseases and Bone. Endocr Rev. 2018; 39: 440-88.

51. Freeman ME, Kanyicska B, Lerant A, Nagy G. Prolactin: structure, function, and regulation of secretion. Physiol Rev. 2000; 80: 1523-631.

52. Levine S, Muneyyirci-Delale O. Stress-Induced Hyperprolactinemia: Pathophysiology and Clinical Approach. Obstet Gynecol Int. 2018; 2018: 9253083.

53. Poletini MO, Szawka RE, Franci CR, Anselmo-Franci JA. Ovarian steroids but not the locus coeruleus regulate stress-induced prolactin secretion in female rats. J Neuroendocrinol. 2006; 18: 938-48.

54. Meerlo P, Easton A, Bergmann BM, Turek FW. Restraint increases prolactin and REM sleep in C57BL/6J mice but not in BALB/cJ mice. Am J Physiol Regul Integr Comp Physiol. 2001; 281: R846-54.

55. Kirk SE, Xie TY, Steyn FJ, Grattan DR, Bunn SJ. Restraint stress increases prolactin-mediated phosphorylation of signal transducer and activator of transcription 5 in the hypothalamus and adrenal cortex in the male mouse. J Neuroendocrinol. 2017; 29.

56. Jaroenporn S, Nagaoka K, Kasahara C, Ohta R, Watanabe G, Taya K. Physiological roles of prolactin in the adrenocortical response to acute restraint stress. Endocr J. 2007; 54: 703-11.

57. Kant GJ, Mougey EH, Pennington LL, Meyerhoff JL. Graded footshock stress elevates pituitary cyclic AMP and plasma beta-endorphin, beta-LPH corticosterone and prolactin. Life Sci. 1983; 33: 2657-63.

58. Siegel RA, Duker EM, Pahnke U, Wuttke W. Stress-induced changes in cholecystokinin and substance $\mathrm{P}$ concentrations in discrete regions of the rat hypothalamus. Neuroendocrinology. 1987; 46: 75-81.

59. Windle RJ, Wood S, Shanks N, Perks P, Conde GL, da Costa AP, et al. Endocrine and behavioural responses to noise stress: comparison of virgin and lactating female rats during non-disrupted maternal activity. J Neuroendocrinol. 1997; 9: 407-14.

60. Clément-Lacroix P, Ormandy C, Lepescheux L, Ammann P, Damotte D, Goffin V, et al. Osteoblasts are a new target for prolactin: analysis of bone formation in prolactin receptor knockout mice. Endocrinology. 1999; 140: 96-105.

61. Wongdee K, Tulalamba W, Thongbunchoo J, Krishnamra N, Charoenphandhu N. Prolactin alters the mRNA expression of osteoblast-derived osteoclastogenic factors in osteoblast-like UMR106 cells. Mol Cell Biochem. 2011; 349: 195-204.

62. Seriwatanachai D, Thongchote $\mathrm{K}$, Charoenphandhu N, Pandaranandaka J, Tudpor K, Teerapornpuntakit J, et al. Prolactin directly enhances bone turnover by raising osteoblast-expressed receptor activator of nuclear factor kappaB ligand/osteoprotegerin ratio. Bone. 2008; 42: 535-46.

63. Coss D, Yang L, Kuo CB, Xu X, Luben RA, Walker AM. Effects of prolactin on osteoblast alkaline phosphatase and bone formation in the developing rat. Am J Physiol Endocrinol. 2000; 279: E1216-E25.

64. Ledesma-Colunga MG, Adan N, Ortiz G, Solis-Gutierrez M, Lopez-Barrera F, Martinez de la Escalera G, et al. Prolactin blocks the expression of receptor activator of nuclear factor kappaB ligand and reduces osteoclastogenesis and bone loss in murine inflammatory arthritis. Arthritis Res Ther. 2017; 19: 93.

65. Zadrozna-Sliwka B, Bolanowski M, Kaluzny M, Syrycka J. Bone mineral density and bone turnover in hyperprolactinaemia of various origins. Endokrynol Pol. 2007; 58: 116-22.

66. Kayath MJ, Lengyel AM, Vieira JG. Prevalence and magnitude of osteopenia in patients with prolactinoma. Braz J Med Biol Res. 1993; 26: 933-41.

67. Kajantie E, Phillips DI. The effects of sex and hormonal status on the physiological response to acute psychosocial stress. Psychoneuroendocrinology. 2006; 31: 151-78.

68. Herrera AY, Hodis HN, Mack WJ, Mather M. Estradiol Therapy After Menopause Mitigates Effects of Stress on Cortisol and Working Memory. J Clin Endocrinol Metab. 2017; 102: 4457-66.

69. Bromberger JT, Matthews KA, Schott LL, Brockwell S, Avis NE, Kravitz HM, et al. Depressive symptoms during the menopausal transition: the Study of Women's Health Across the Nation (SWAN). J Affect Disord. 2007; 103: 267-72.

70. Hedgeman E, Hasson RE, Karvonen-Gutierrez CA, Herman WH, Harlow SD. Perceived stress across the midlife: longitudinal changes among a diverse sample of women, the Study of Women's health Across the Nation (SWAN). Womens Midlife Health. 2018; 4: 2.

71. Woods NF, Mitchell ES, Smith-Dijulio K. Cortisol levels during the menopausal transition and early postmenopause: observations from the Seattle Midlife Women's Health Study. Menopause. 2009; 16: 708-18.

72. Chan CY, Subramaniam S, Mohamed N, Ima-Nirwana S, Muhammad N, Fairus A, et al. Determinants of Bone Health Status in a Multi-Ethnic Population in Klang Valley, Malaysia. Int J Environ Res Public Health. 2020; 17: E384.

73. Mohamad NV, Soelaiman IN, Chin KY. A concise review of testosterone and bone health. Clin Interv Aging. 2016; 11: 1317-24.

74. Khosla S, Monroe DG. Regulation of Bone Metabolism by Sex Steroids. Cold Spring Harb Perspect Med. 2018; 8.

75. Chin KY, Ima-Nirwana S. Sex steroids and bone health status in men. Int J Endocrinol. 2012; 2012: 208719.

76. Retana-Marquez S, Bonilla-Jaime H, Vazquez-Palacios G, Martinez-Garcia R, Velazquez-Moctezuma J. Changes in masculine sexual behavior, corticosterone and testosterone in response to acute and chronic stress in male rats. Horm Behav. 2003; 44: 327-37.

77. Chrousos GP, Torpy DJ, Gold PW. Interactions between the hypothalamic-pituitary-adrenal axis and the female reproductive system: clinical implications. Ann Intern Med. 1998; 129: 229-40.

78. Adam TC, Epel ES. Stress, eating and the reward system. Physiol Behav. 2007; 91: 449-58

79. Bjorntorp P. Do stress reactions cause abdominal obesity and comorbidities? Obes Rev. 2001; 2: 73-86.

80. Michels N, Sioen I, Ruige J, De Henauw S. Children's psychosocial stress and emotional eating: A role for leptin? Int J Eat Disord. 2017; 50: 471-80.

81. Iwaniec UT, Boghossian S, Lapke PD, Turner RT, Kalra SP. Central leptin gene therapy corrects skeletal abnormalities in leptin-deficient ob/ob mice. Peptides. 2007; 28: 1012-9.

82. Hamrick MW, Pennington C, Newton D, Xie D, Isales C. Leptin deficiency produces contrasting phenotypes in bones of the limb and spine. Bone. 2004; 34: 376-83.

83. Ducy P, Amling M, Takeda S, Priemel M, Schilling AF, Beil FT, et al. Leptin inhibits bone formation through a hypothalamic relay: a central control of bone mass. Cell. 2000; 100: 197-207.

84. Pogoda P, Egermann M, Schnell JC, Priemel M, Schilling AF, Alini M, et al. Leptin inhibits bone formation not only in rodents, but also in sheep. J Bone Miner Res. 2006; 21: 1591-9.

85. Takeda S, Elefteriou F, Levasseur R, Liu X, Zhao L, Parker KL, et al. Leptin regulates bone formation via the sympathetic nervous system. Cell. 2002; 111: 305-17.

86. Burguera B, Hofbauer LC, Thomas T, Gori F, Evans GL, Khosla S, et al. Leptin reduces ovariectomy-induced bone loss in rats. Endocrinology. 2001; 142: 3546-53.

87. Baek K, Bloomfield SA. Beta-adrenergic blockade and leptin replacement effectively mitigate disuse bone loss. J Bone Miner Res. 2009; 24: 792-9.

88. Martin A, de Vittoris R, David V, Moraes R, Bégeot M, Lafage-Proust MH, et al. Leptin modulates both resorption and formation while preventing disuse-induced bone loss in tail-suspended female rats. Endocrinology. 2005; 146: 3652-9.

89. Culhane KJ, Belina ME, Sims JN, Cai Y, Liu Y, Wang PSP, et al. Parathyroid Hormone Senses Extracellular Calcium To Modulate Endocrine Signaling upon Binding to the Family B GPCR Parathyroid Hormone 1 Receptor. ACS Chem Biol. 2018; 13: 2347-58.

90. Terzioglu-Usak S, Elibol B, Dalli T, Guler C, Aysan E. Effect of Restraint Stress on Plasma PTH Concentration and Its Molecular Targets Expressions in Wistar Rats. Int J Endocrinol Metab. 2018; 16: e66979.

91. Poole KE, Reeve J. Parathyroid hormone - a bone anabolic and catabolic agent. Curr Opin Pharmacol. 2005; 5: 612-7.

92. Locklin RM, Khosla S, Turner RT, Riggs BL. Mediators of the biphasic responses of bone to intermittent and continuously administered parathyroid hormone. J Cell Biochem. 2003; 89: 180-90.

93. Ma YL, Cain RL, Halladay DL, Yang X, Zeng O, Miles RR, et al. Catabolic effects of continuous human PTH (1--38) in vivo is associated with sustained stimulation of RANKL and inhibition of osteoprotegerin and gene-associated bone formation. Endocrinology. 2001; 142: 4047-54

94. Ensel WM, Lin N. Physical fitness and the stress process. J Community Psychol. 2004; 32: 81-101

95. Shin Y, Kim Y. Psychological Stress Accompanied by a Low-Variety Diet Is Positively Associated with Type 2 Diabetes in Middle-Aged Adults. Nutrients. 2020; 12: 2612.

96. Ramchandani VA, Stangl BL, Blaine SK, Plawecki MH, Schwandt ML, Kwako LE, et al. Stress vulnerability and alcohol use and consequences: From human laboratory studies to clinical outcomes. Alcohol (Fayetteville, NY). 2018; 72: $75-88$

97. Jahnel T, Ferguson SG, Shiffman S, Schüz B. Daily stress as link between disadvantage and smoking: an ecological momentary assessment study. BMC Public Health. 2019; 19: 1284

98. Cheon Y, Park J, Jeong BY, Park EY, Oh J-K, Yun EH, et al. Factors associated with psychological stress and distress among Korean adults: the results from Korea National Health and Nutrition Examination Survey. Scientific reports. 2020; 10: 15134- 
99. Torres OV, O'Dell LE. Stress is a principal factor that promotes tobacco use in females. Prog Neuropsychopharmacol Biol Psychiatry. 2016; 65: 260-8.

100. Hobkirk AL, Krebs NM, Muscat JE. Income as a moderator of psychological stress and nicotine dependence among adult smokers. Addict Behav. 2018; 84: 215-23.

101. Abrahamsen B, Brask-Lindemann D, Rubin KH, Schwarz P. A review of lifestyle, smoking and other modifiable risk factors for osteoporotic fractures. Bonekey Rep. 2014; 3: 574.

102. Wynder EL, Hoffmann D. Tobacco and health: a societal challenge. N Engl J Med. 1979; 300: 894-903.

103. Kallala R, Barrow J, Graham SM, Kanakaris N, Giannoudis PV. The in vitro and in vivo effects of nicotine on bone, bone cells and fracture repair. Expert Opin Drug Saf. 2013; 12: 209-33.

104. Kim BS, Kim SJ, Kim HJ, Lee SJ, Park YJ, Lee J, et al. Effects of nicotine on proliferation and osteoblast differentiation in human alveolar bone marrow-derived mesenchymal stem cells. Life Sci. 2012; 90: 109-15.

105. Kamer AR, El-Ghorab N, Marzec N, Margarone JE, 3rd, Dziak R. Nicotine induced proliferation and cytokine release in osteoblastic cells. Int J Mol Med. 2006; 17 : $121-7$

106. Hapidin H, Othman F, Soelaiman IN, Shuid AN, Luke DA, Mohamed N. Negative effects of nicotine on bone-resorbing cytokines and bone histomorphometric parameters in male rats. J Bone Miner Metab. 2007; 25: 93-8.

107. Luo G, Li F, Li X, Wang Z-G, Zhang B. TNF-a and RANKL promote osteoclastogenesis by upregulating RANK via the NF-kB pathway. Mol Med Rep. 2018; 17: 6605-11.

108. Henemyre CL, Scales DK, Hokett SD, Cuenin MF, Peacock ME, Parker MH, et al. Nicotine stimulates osteoclast resorption in a porcine marrow cell model. J Periodontol. 2003; 74: 1440-6.

109. Aspera-Werz RH, Ehnert S, Heid D, Zhu S, Chen T, Braun B, et al. Nicotine and Cotinine Inhibit Catalase and Glutathione Reductase Activity Contributing to the Impaired Osteogenesis of SCP-1 Cells Exposed to Cigarette Smoke. Oxid Med Cell Longev. 2018; 2018: 3172480.

110. Li Y, Yu C, Shen G, Li G, Shen J, Xu Y, et al. Sirt3-MnSOD axis represses nicotine-induced mitochondrial oxidative stress and mtDNA damage in osteoblasts. Acta Biochim Biophys Sin (Shanghai). 2015; 47: 306-12.

111. Kim SJ, Kim MJ, Yoon SG, Myong JP, Yu HW, Chai YJ, et al. Impact of smoking on thyroid gland: dose-related effect of urinary cotinine levels on thyroid function and thyroid autoimmunity. Sci Rep. 2019; 9: 4213.

112. Soldin OP, Goughenour BE, Gilbert SZ, Landy HJ, Soldin SJ. Thyroid hormone levels associated with active and passive cigarette smoking. Thyroid. 2009; 19: 817-23.

113. Chin K-Y, Ima-Nirwana S, Mohamed IN, Aminuddin A, Johari MH, Ngah WZW. Thyroid-Stimulating Hormone Is Significantly Associated with Bone Health Status in Men. Int J Med Sci. 2013; 10: 857-63.

114. Vestergaard P. Smoking and thyroid disorders-a meta-analysis. Eur J Endocrinol. 2002; 146: 153-61.

115. Delitala AP, Scuteri A, Doria C. Thyroid Hormone Diseases and Osteoporosis. J Clin Med. 2020; 9: 1034.

116. Direk N, Newson RS, Hofman A, Kirschbaum C, Tiemeier H. Short and long-term effects of smoking on cortisol in older adults. Int J Psychophysiol. 2011; 80: 157-60.

117. Jorde R, Saleh F, Figenschau Y, Kamycheva E, Haug E, Sundsfjord J. Serum parathyroid hormone (PTH) levels in smokers and non-smokers. The fifth Tromsø study \%J European Journal of Endocrinology eur j endocrinol. Eur J Endocrinol. 2005; 152: 39 .

118. Jandikova H, Duskova M, Simunkova K, Racz B, Hill M, Kralikova E, et al. The steroid spectrum during and after quitting smoking. Physiol Res. 2015; 64: S211-8.

119. Schiller CE, Saladin ME, Gray KM, Hartwell KJ, Carpenter MJ. Association between ovarian hormones and smoking behavior in women. Exp Clin Psychopharmacol. 2012; 20: 251-7.

120. Brand JS, Chan MF, Dowsett M, Folkerd E, Wareham NJ, Luben RN, et al. Cigarette smoking and endogenous sex hormones in postmenopausal women. J Clin Endocrinol Metab. 2011; 96: 3184-92.

121. El Ansari W, Berg-Beckhoff G. Nutritional Correlates of Perceived Stress among University Students in Egypt. Int J Environ Res Public Health. 2015; 12: 14164-76.

122. Errisuriz VL, Pasch KE, Perry CL. Perceived stress and dietary choices: The moderating role of stress management. Eating Behaviors. 2016; 22: 211-6.

123. Laugero KD, Falcon LM, Tucker KL. Relationship between perceived stress and dietary and activity patterns in older adults participating in the Boston Puerto Rican Health Study. Appetite. 2011; 56: 194-204.

124. Qiu R, Cao WT, Tian HY, He J, Chen GD, Chen YM. Greater Intake of Fruit and Vegetables Is Associated with Greater Bone Mineral Density and Lower Osteoporosis Risk in Middle-Aged and Elderly Adults. PLoS One. 2017; 12: e0168906.

125. Brondani JE, Comim FV, Flores LM, Martini LA, Premaor MO. Fruit and vegetable intake and bones: A systematic review and meta-analysis. PLoS One. 2019; 14: e0217223.

126. Shen CL, von Bergen V, Chyu MC, Jenkins MR, Mo H, Chen $\mathrm{CH}$, et al. Fruits and dietary phytochemicals in bone protection. Nutr Res. 2012; 32: 897-910.

127. Tucker KL, Hannan MT, Kiel DP. The acid-base hypothesis: diet and bone in the Framingham Osteoporosis Study. Eur J Nutr. 2001; 40: 231-7.
128. Caudarella R, Vescini F, Rizzoli E, Francucci CM. Salt intake, hypertension, and osteoporosis. J Endocrinol Investig. 2009; 32: 15-20.

129. Dar HY, Singh A, Shukla P, Anupam R, Mondal RK, Mishra PK, et al. High dietary salt intake correlates with modulated Th17-Treg cell balance resulting in enhanced bone loss and impaired bone-microarchitecture in male mice. Sci Rep. 2018; 8: 2503.

130. Dargent-Molina P, Poitiers F, Bréart G. In elderly women weight is the best predictor of a very low bone mineral density: evidence from the EPIDOS study. Osteoporos Int. 2000; 11: 881-8.

131. Chin K-Y, Wong SK, Ekeuku SO, Pang K-L. Relationship Between Metabolic Syndrome and Bone Health - An Evaluation of Epidemiological Studies and Mechanisms Involved. Diabetes Metab Syndr Obes. 2020; 13: 3667-90.

132. Heo M, Pietrobelli A, Fontaine KR, Sirey JA, Faith MS. Depressive mood and obesity in US adults: comparison and moderation by sex, age, and race. Int J Obes (Lond). 2006; 30: 513-9.

133. Weber-Hamann B, Hentschel F, Kniest A, Deuschle M, Colla M, Lederbogen F, et al. Hypercortisolemic depression is associated with increased intraabdominal fat. Psychosom Med. 2002; 64: 274-7.

134. Ljung T, Holm G, Friberg P, Andersson B, Bengtsson BA, Svensson J, et al. The activity of the hypothalamic-pituitary-adrenal axis and the sympathetic nervous system in relation to waist/hip circumference ratio in men. Obes Res. 2000; 8: 487-95.

135. Lim J, Park HS. Relationship between underweight, bone mineral density and skeletal muscle index in premenopausal Korean women. Int J Clin Pract. 2016; 70: 462-8.

136. Sinha R. How does stress lead to risk of alcohol relapse? Alcohol Res. 2012; 34: 432-40.

137. Schuckit MA. Alcohol-use disorders. Lancet. 2009; 373: 492-501.

138. Luo Z, Liu Y, Liu Y, Chen H, Shi S, Liu Y. Cellular and molecular mechanisms of alcohol-induced osteopenia. Cell Mol Life Sci. 2017; 74: 4443-53.

139. Maurel DB, Boisseau N, Benhamou CL, Jaffre C. Alcohol and bone: review of dose effects and mechanisms. Osteoporos Int. 2012; 23: 1-16.

140. Wezeman FH, Gong Z. Bone marrow triglyceride accumulation and hormonal changes during long-term alcohol intake in male and female rats. Alcohol Clin Exp Res. 2001; 25: 1515-22.

141. Mohan S, Richman C, Guo R, Amaar Y, Donahue LR, Wergedal J, et al. Insulin-like growth factor regulates peak bone mineral density in mice by both growth hormone-dependent and -independent mechanisms. Endocrinology. 2003; 144: 929-36.

142. Dai J, Lin D, Zhang J, Habib P, Smith P, Murtha J, et al. Chronic alcohol ingestion induces osteoclastogenesis and bone loss through IL-6 in mice. J Clin Invest. 2000; 106: 887-95.

143. Yao Z, Zhang J, Dai J, Keller ET. Ethanol activates NFkappaB DNA binding and p56lck protein tyrosine kinase in human osteoblast-like cells. Bone. 2001; 28: 167-73.

144. Wahl EC, Aronson J, Liu L, Liu Z, Perrien DS, Skinner RA, et al. Chronic ethanol exposure inhibits distraction osteogenesis in a mouse model: role of the TNF signaling axis. Toxicol Appl Pharmacol. 2007; 220: 302-10.

145. Gonzalez-Reimers E, Martin-Gonzalez C, de la Vega-Prieto MJ, Pelazas-Gonzalez R, Fernandez-Rodriguez C, Lopez-Prieto J, et al. Serum sclerostin in alcoholics: a pilot study. Alcohol Alcohol. 2013; 48: 278-82.

146. Bonewald LF, Johnson ML. Osteocytes, mechanosensing and Wnt signaling. Bone. 2008; 42: 606-15

147. Bedard K, Krause KH. The NOX family of ROS-generating NADPH oxidases: physiology and pathophysiology. Physiol Rev. 2007; 87: 245-313.

148. Chen JR, Shankar K, Nagarajan S, Badger TM, Ronis MJ. Protective effects of estradiol on ethanol-induced bone loss involve inhibition of reactive oxygen species generation in osteoblasts and downstream activation of the extracellular signal-regulated kinase/signal transducer and activator of transcription $3 /$ receptor activator of nuclear factor-kappaB ligand signaling cascade. J Pharmacol Exp Ther. 2008; 324: 50-9.

149. Dorgan JF, Reichman ME, Judd JT, Brown C, Longcope C, Schatzkin A, et al. The relation of reported alcohol ingestion to plasma levels of estrogens and androgens in premenopausal women (Maryland, United States). Cancer Causes Control. 1994; 5: 53-60.

150. Diamond T, Stiel D, Lunzer M, Wilkinson M, Posen S. Ethanol reduces bone formation and may cause osteoporosis. Am J Med. 1989; 86: 282-8.

151. Maneesh M, Dutta S, Chakrabarti A, Vasudevan DM. Alcohol abuse-duration dependent decrease in plasma testosterone and antioxidants in males. Indian J Physiol Pharmacol. 2006; 50: 291-6.

152. Park KY, Park HK, Hwang HS. Relationship between abdominal obesity and alcohol drinking pattern in normal-weight, middle-aged adults: the Korea National Health and Nutrition Examination Survey 2008-2013. Public Health Nutr. 2017; 20: 2192-200.

153. Lutz R, Stults-Kolehmainen M, Bartholomew J. Exercise caution when stressed: Stages of change and the stress-exercise participation relationship. Psychol Sport Exerc. 2010; 11: 560-7.

154. Chin KY, Soelaiman IN, Mohamed IN, Ibrahim S, Wan Ngah WZ. The effects of age, physical activity level, and body anthropometry on calcaneal speed of sound value in men. Arch Osteoporos. 2012; 7: 135-45.

155. Chan CY, Subramaniam S, Mohamed N, Ima-Nirwana S, Muhammad N, Fairus A, et al. Determinants of Bone Health Status in a Multi-Ethnic Population in Klang Valley, Malaysia. Int J Environ Res Public Health. 2020; 17. 
156. Ladabaum U, Mannalithara A, Myer PA, Singh G. Obesity, abdominal obesity, physical activity, and caloric intake in US adults: 1988 to 2010. Am J Med. 2014; 127: 717-27.e12.

157. Eyre HA, Papps E, Baune BT. Treating depression and depression-like behavior with physical activity: an immune perspective. Front Psychiatry. 2013; 4: 3 .

158. Kelley GA, Kelley KS, Kohrt WM. Effects of ground and joint reaction force exercise on lumbar spine and femoral neck bone mineral density in postmenopausal women: a meta-analysis of randomized controlled trials. BMC Musculoskelet Disord. 2012; 13: 177.

159. del Real A, Riancho-Zarrabeitia L, López-Delgado L, Riancho JA. Epigenetics of Skeletal Diseases. Curr Osteoporos Rep. 2018; 16: 246-55.

160. Cuffe JS, O'Sullivan L, Simmons DG, Anderson ST, Moritz KM. Maternal corticosterone exposure in the mouse has sex-specific effects on placental growth and mRNA expression. Endocrinology. 2012; 153: 5500-11.

161. Jensen Peña $C$, Monk $C$, Champagne FA. Epigenetic effects of prenatal stress on $11 \beta$-hydroxysteroid dehydrogenase- 2 in the placenta and fetal brain. PLoS One. 2012; 7: e39791.

162. Vieau D, Sebaai N, Léonhardt M, Dutriez-Casteloot I, Molendi-Coste O, Laborie $\mathrm{C}$, et al. HPA axis programming by maternal undernutrition in the male rat offspring. Psychoneuroendocrinology. 2007; 32 Suppl 1: S16-20.

163. Azuma K, Ogura M, Kondo H, Suzuki A, Hayashi S, Iinuma M, et al. Maternal Active Mastication during Prenatal Stress Ameliorates Prenatal Stress-Induced Lower Bone Mass in Adult Mouse Offspring. Int J Med Sci. 2017; 14: 348-55.

164. Baum A, Garofalo JP, Yali AM. Socioeconomic status and chronic stress. Does stress account for SES effects on health? Ann N Y Acad Sci. 1999; 896: 131-44.

165. Myong J-P, Kim H-R, Choi SE, Koo J-W. The Effect of Socioeconomic Position on Bone Health Among Koreans by Gender and Menopausal Status. Calcif Tissue Int. 2012; 90: 488-95.

166. Kong S, So W-Y. Gender differences in body composition, physical activity level, physical fitness, and bone mineral density among elderly individuals living alone compared to those living with their spouses. J Men's Health. 2017; 13: e60-e7

167. Brennan SL, Pasco JA, Urquhart DM, Oldenburg B, Hanna F, Wluka AE. The association between socioeconomic status and osteoporotic fracture in population-based adults: a systematic review. Osteoporos Int. 2009; 20: 1487-97.

168. Elgar FJ, Gariépy G, Torsheim T, Currie C. Early-life income inequality and adolescent health and well-being. Soc Sci Med. 2017; 174: 197-208.

169. Soteriades ES, DiFranza JR. Parent's socioeconomic status, adolescents' disposable income, and adolescents' smoking status in Massachusetts. Am J Public Health. 2003; 93: 1155-60.

170. Liu Y, Lintonen T, Tynjälä J, Villberg J, Välimaa R, Ojala K, et al. Socioeconomic differences in the use of alcohol and drunkenness in adolescents: Trends in the Health Behaviour in School-aged Children study in Finland 1990-2014. Scand J Public Health. 2016; 46: 102-11. 